\title{
Is Social Security behind the Collapse of Personal Saving?
}

\author{
FRANK N. CALIENDO
}

CESIFO WORKING PAPER No. 2746

CAtegory 2: Public CHOICE

August 2009

Presented at CESifo Venice Summer InStitute, July 2009

\footnotetext{
An electronic version of the paper may be downloaded

- from the SSRN website: www.SSRN.com

- from the RePEc website:

- from the CESifo website:

www.RePEc.org

www.CESifo-group.org/wp
} 


\title{
Is Social Security behind the Collapse of Personal Saving?
}

\begin{abstract}
This paper considers the quantitative role of growth in the size of the social security program in contributing to the collapse of personal saving in the U.S. over the last few decades. Using a calibrated, general equilibrium life-cycle model this paper shows that social security may not be to blame. Specifically, the model predicts that a 50-percent increase in the social security tax rate (as in the U.S. over the last half century) produces a modest decline in the personal saving rate from 10 percent down to 9.6 percent. This result runs counter to some popular opinion.
\end{abstract}

JEL Code: E21, D91, H55.

Keywords: NIPA personal saving rate, social security, life-cycle permanent-income model, general equilibrium calibration.

\author{
Frank N. Caliendo \\ Utah State University \\ Jon M. Huntsman School of Business \\ USA - Logan, UT 84322-3565 \\ frank.caliendo@usu.edu
}

July 27, 2009

I thank Kevin Lansing for the use of his data, Emin Gahramanov for research assistance, and Jim Feigenbaum, Nathalie Mathieu-Bolh, Stephen Zeldes, Laurence Kotlikoff, and especially Fabian Kindermann for helpful comments. I gratefully acknowledge financial support from the CESifo Venice Summer Institute. 
"[A] commonly referenced argument for the decline in the personal saving rate emphasizes the growing importance of Social Security..."

Roger W. Ferguson, Jr., Vice Chairman, Board of Governors, Federal Reserve System

October 6, 2004

\section{Introduction}

What caused the collapse of the personal saving rate in the National Income and Product Accounts (NIPA) (see Figure 1), from around 10 percent in the 1970's to nearly zero at present? This paper considers the quantitative role of the social security program in contributing to the declining personal saving rate. The social security tax rate has risen about 50 percent over the same period of time (see Figure 2). In the above quote, Vice Chairman Ferguson points out that growth in the size of the social security program is widely believed to be an important part of the explanation for the collapse in the personal saving rate. The simple general equilibrium model used in this paper does not lend any support to this popular hypothesis.

Figure 1. The U.S. NIPA Personal Saving Rate

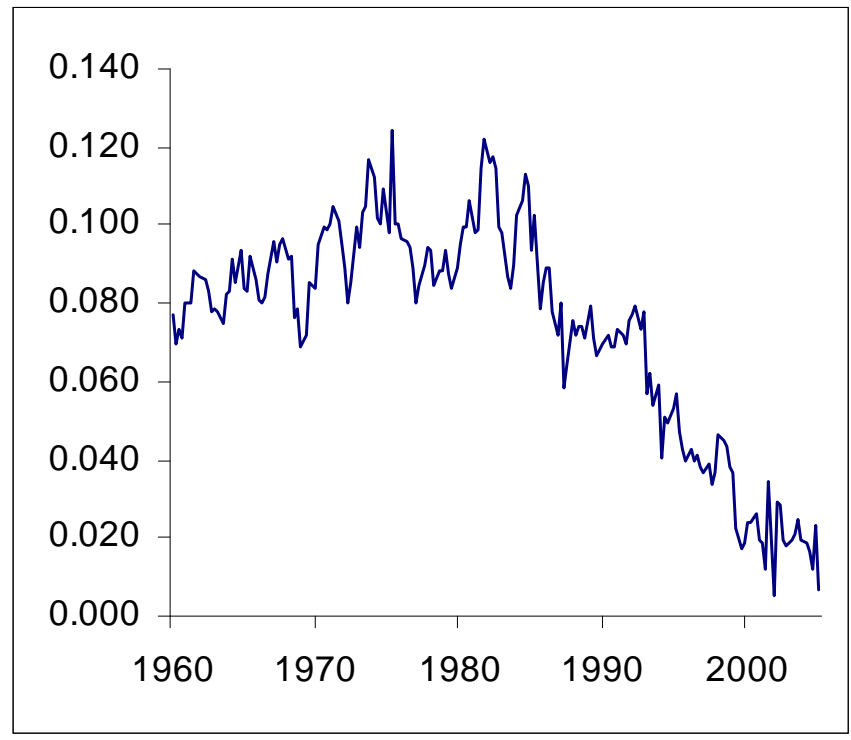

NOTE: From the National Income and Product Accounts. 
Figure 2. The U.S. OASI Social Security Tax Rate

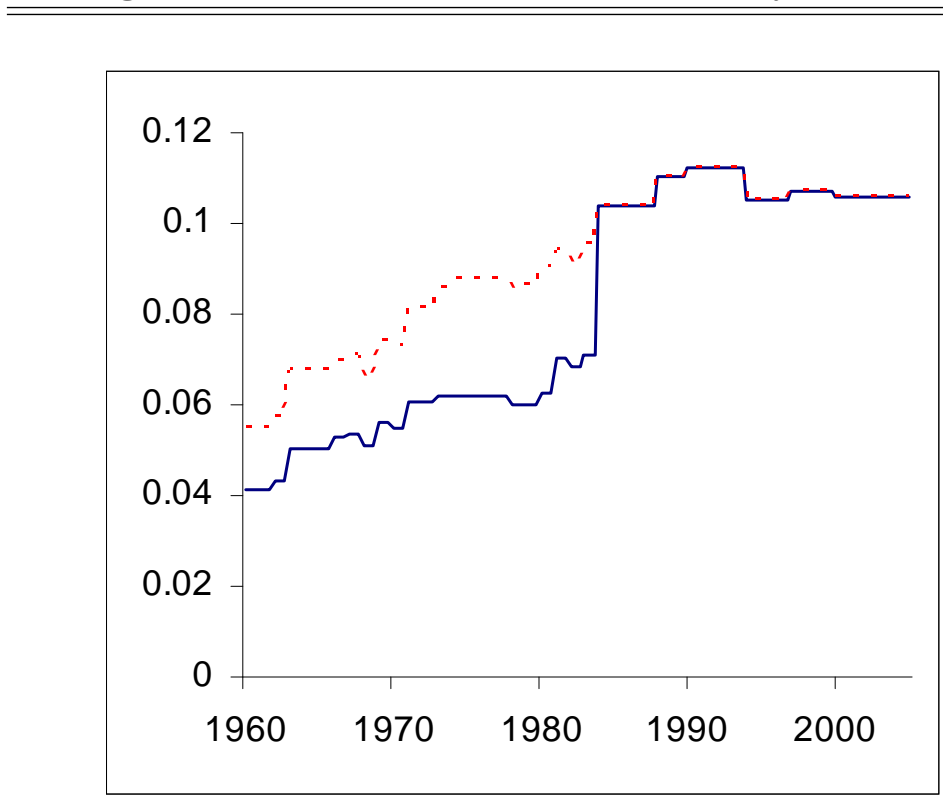

NOTE: OASI tax rate for self-employed individuals is the solid line, and the dashed line is the combined employee-employer OASI rate. Disability and medicare components are not included in these series (including these additional components would make the growth even more pronounced).

This paper begins by constructing a personal saving rate that is compatible with the one from the NIPA by carefully aggregating across both working-age and retirement-age cohorts, while properly treating retirement account contributions and distributions from both private and public pensions in the same manner as in the NIPA. Factor prices are determined competitively, and aggregate capital is the sum of household capital across and within many overlapping generations of continuous-time permanent-income consumers. The variables of the model are calibrated to match some of the salient features of the U.S. macroeconomic data. The model successfully reproduces a personal saving rate, capital-output ratio, real rate of return, and worker-to-retiree ratio that fit the data well. To see the quantitative general equilibrium effect of social security on personal saving, I compare competitive equilibria with different rates of social security taxation. The model predicts that a 50-percent increase in the social security tax rate (just as in the U.S. over the last few decades) may be responsible for only $1 / 2$ of a percentage point of the decline in the personal saving rate - the saving rate drops from 10 percent to 9.6 percent in the model. This result is surprisingly persistent across a wide space of parameter values. Finally, this paper shows that social security's effect quadruples in a partial equilibrium setting, thus demonstrating the potential importance of the general equilibrium approach to this particular research question. However, a four-fold increase of 
an already very small number is of course still small relative to the overall drop in the NIPA saving rate.

Given that social security may play only a minor role in the context of the particular model used here, other possible explanations seem more likely: $(i)$ the aging U.S. population means that more people are drawing down existing assets, (ii) large (realized or unrealized) capital gains in stock and housing markets do not show up as personal income in the NIPA but they may trigger a consumption boom, (iii) the risk-free interest rate has fallen steadily, (iv) credit market innovations have brought easier access to borrowed money, and $(v)$ the rather novel explanation by Reis (2006) that a technology-driven reduction in the cost of acquiring and processing information leads rational consumers to choose shorter periods of inattention, which in turn weakens the precautionary motive for saving. (For more on such alternative mechanisms, see Parker 1999, Munnell, Golub-Sass, and Varani 2005, Marquis 2002, Lansing 2005, Garner 2006, Lusardi, Skinner, and Venti 2001, and Gale and Sabelhaus 1999). The analysis that follows will intentionally abstract from these competing theories in order to isolate the role of social security.

This paper builds on the progress of some other researchers who also study the role of social security in the saving crisis. For example, Parker (1999) considers the link between intergenerational transfers and the consumption boom. The value added in the present study is due to a general equilibrium calibration of a personal saving rate that is compatible with the one in the NIPA, and a computation of the general equilibrium effect of social security on the personal saving rate. Gokhale, Kotlikoff, and Sabelhaus (1996) construct cohort data in order to decompose changes in the U.S. national saving rate and they conclude that much of the drop in national saving in the post-war era is due to increased government transfers from the young to the old. However, their focus is on national saving rather than personal saving, and, as they put it, "personal saving bears no necessary relationship to national saving," so it is difficult to know whether their conclusions can be generalized to personal saving. In addition to their focus on a different aggregate, they also use different modeling techniques and this may also explain the difference in the results. While their study is an impressive example of careful data construction and analysis, it is done in partial equilibrium. On the other hand, the present paper is an attempt to use a calibrated general equilibrium model to estimate the quantitative impact of social security on personal saving. Finally, they focus on the period 1960-1990, and I study the more recent period 1970-2005 which corresponds to the drop in personal saving.

In sum, this paper is a general-equilibrium quantitative-theoretic investigation of the role of social security in contributing to the declining personal saving rate. The calibrated model provides a decent fit with a few key features of the U.S. economy and especially with the NIPA personal saving rate, and so it may be a suitable instrument for studying this research question. And, even though growth in social security taxation has been extreme in the U.S., the model provides evidence that social security may not be responsible for much of the collapse in NIPA personal saving. This result runs counter to some popular 
opinion. ${ }^{1}$ On the other hand, the model used here is very simple, and adding more realistic complications - which are discussed in the concluding section of the paper - could very well change the results. This paper should be interpreted as one small part of a large research agenda that will attempt to understand the effect of social security on NIPA personal saving in the context of calibrated general equilibrium models.

\section{A Simple, Dynamic Model of NIPA Personal Saving}

The model below is a simple variant of Bullard and Feigenbaum's (2007) macroeconomic model. Both models feature overlapping generations of continuoustime permanent-income consumers. The two models differ mostly in application. Bullard and Feigenbaum abstract from population growth and study the role of leisure as a solution to the consumption-hump puzzle. Alternatively, I focus on the growth effects since they are the key determinants of aggregate personal saving, while abstracting from the household leisure choice. Mortality risk and age-based productivity effects are also not examined here.

Moreover, the model used here is not new. It is nearly identical to the model in Caliendo and Gahramanov (2008) except for a few accounting issues relating to the treatment of NIPA income and saving. Hence, the contribution of this paper rests on the application of the model to an important quantitative question, rather than any fundamental contribution to modeling.

\subsection{Partial Equilibrium}

Calendar time is continuous and is indexed by $t$. All people enter the workforce at birth and work for $T$ years, and the lifespan is $\bar{T}$ years. At each instant a new cohort is born and an old cohort dies. The size of each successive cohort grows at rate $n$ (and hence the total population grows at rate $n$ ), so that the size of a cohort born at time $\tau$ is $N(\tau)=N(t) e^{n(\tau-t)}$, where $N(t)$ is the size of the cohort born at time $t$. Thus at any time $t$ the number of workers is $\int_{t-T}^{t} N(t) e^{n(\tau-t)} d \tau$, and the number of retirees is $\int_{t-\bar{T}}^{t-T} N(t) e^{n(\tau-t)} d \tau$. Let $R$ be the ratio of workers to retirees, which is time invariant: $R=\left(1-e^{-n T}\right) /\left(e^{-n T}-e^{-n \bar{T}}\right)$. These demographic assumptions intentionally abstract from "lumpy" age distributions like the baby-boom phenomenon in order to isolate the pure role of growth in social security.

A representative individual from cohort $\tau$ is born and starts work at time $\tau$, retires at $\tau+T$, and then dies at $\tau+\bar{T}$. The agent takes the economy-wide

\footnotetext{
${ }^{1}$ This finding may have useful policy implications, given that policy makers may opt to raise social security taxes - either explicitly through an increase in the tax rate, or implicitly through an increase in the age of full eligibility or an increase in the earnings cap-in response to ongoing solvency concerns. While such action may have important consequences for household welfare, this paper shows that the NIPA personal saving rate would not respond much.
} 
wage $w(t)$ as given, and $w(t)$ grows at a constant rate $x$ according to the stable competitive equilibrium that will be explained later. Every worker alive at time $t$ earns $w(t)$, implying that younger cohorts have higher levels of lifetime wealth or permanent income than older cohorts. The agent's savings account, $k(t, \tau)$, grows at the endogenously-determined risk-free real rate of return, $r$. Again, the agent takes this as given, and it will be shown below that a constant rate of return is a feature of the competitive equilibrium under consideration. Following Bullard and Feigenbaum (2007), agents purchase claims on capital by lending directly to firms, and they also enter into debt contracts with agents from other cohorts; the rate of return is the same in both markets. Agents can also sell their claims on the capital of firms to agents from other cohorts. For example, a retiree who wishes to consume more than his income (from claims on capital plus social security benefits), can liquidate his claims and consume the proceeds. Likewise, a young agent who wants to spend more than he earns can borrow from middle-age savers. Hence, aggregate household saving (total demand for capital less demand for borrowed funds) flows to firms and is converted to capital, and firms then compensate households according to the productivity of that capital, less the amount needed to cover depreciation. Because firms use part of their revenues to repair depreciated capital, the resale value of the agent's claims on capital always equals the value of the initial loan to the firm. The model abstracts from differential NIPA treatment of capital gains versus interest and dividend income, because this is a competing explanation for the collapse in personal saving.

The social security tax rate is $\theta$ and workers bear the full burden since labor is supplied inelastically. Following Feldstein (1985), Feldstein (1987), Cremer, De Donder, Maldonado, and Pestieau (2006), and many others, pay-as-you-go social security benefits per retiree at time $t$ are $b(t)=\theta w(t) R$. Note that $w(t)$ and $b(t)$ depend only on calendar time, and not on the birth date of the agent. The environment is inflation free.

The optimization problem is standard, and it follows Caliendo and Gahramanov (2008) exactly, up to equation (10). A given consumer solves the following control problem ${ }^{2}$

$$
\max \int_{\tau}^{\tau+\bar{T}} e^{-\rho(t-\tau)} u(c(t, \tau)) d t
$$

subject to the laws of motion for the savings account,

$$
\frac{d k(t, \tau)}{d t}=r k(t, \tau)+(1-\theta) w(t)-c(t, \tau) \text { for } t \in[\tau, \tau+T]
$$

\footnotetext{
${ }^{2}$ The assumption of life-cycle permanent-income consumers who are fully rational will stack the cards in favor of finding a role for social security in the saving crisis. Because these consumers have perfect foresight, their personal saving should be the most responsive to a larger social security program. This contrasts with say a Keynesian rule-of-thumb consumer who saves from pre-tax wage income. Such a consumer would be completely unresponsive to a larger social security program and would instead accumulate just as much capital as in a world with a small social security program.
} 


$$
\frac{d k(t, \tau)}{d t}=r k(t, \tau)+b(t)-c(t, \tau) \text { for } t \in[\tau+T, \tau+\bar{T}]
$$

a pair of boundary conditions,

$$
\begin{gathered}
k(\tau, \tau)=0 \\
k(\tau+\bar{T}, \tau)=0
\end{gathered}
$$

the balanced budget requirement,

$$
b(t)=\theta w(t) R
$$

and the age-structure of the population,

$$
R=\left(1-e^{-n T}\right) /\left(e^{-n T}-e^{-n \bar{T}}\right)
$$

The period utility function is of the CRRA variety $u(c(t, \tau))=\frac{c(t, \tau)^{1-\sigma}}{1-\sigma}$, and the discount rate is $\rho$.

The Maximum Principle gives

$$
c^{p}(t, \tau)=\Omega w(\tau) e^{g(t-\tau)}
$$

where $g \equiv \frac{r-\rho}{\sigma}$ and $\Omega$ is invariant to the birth and calendar dates

$$
\Omega \equiv\left\{\frac{(1-\theta)\left[e^{(x-r) T}-1\right]+\theta R\left[e^{(x-r) \bar{T}}-e^{(x-r) T}\right]}{x-r}\right\} \frac{e^{r \bar{T}}(g-r)}{e^{g \bar{T}}-e^{r \bar{T}}}
$$

and the " $p$ " superscript stands for "permanent income." Note that the slope of the permanent-income consumption rule (8) across the life-cycle depends on the parameter $g$, and the level depends on the birth date of the agent; each consumer has the same rate of change in consumption across the life cycle, but younger consumers have profiles that are everywhere higher than older consumers due to growth in the economy-wide wage. We now turn to a derivation of NIPA personal saving.

Using $k(\tau, \tau)=0$, it follows that the solution to (2) is

$$
k(t, \tau)=\frac{(1-\theta) w(\tau)}{x-r}\left[e^{x(t-\tau)}-e^{r(t-\tau)}\right]+\frac{\Omega w(\tau)}{g-r}\left[e^{r(t-\tau)}-e^{g(t-\tau)}\right]
$$

for $t \in[\tau, \tau+T]$. Likewise, using $k(\tau+\bar{T}, \tau)=0$, it follows that the solution to (3) is

$k(t, \tau)=\frac{\theta w(\tau) R}{x-r}\left[e^{x(t-\tau)}-e^{x \bar{T}+r(t-\tau-\bar{T})}\right]-\frac{\Omega w(\tau)}{g-r}\left[e^{g(t-\tau)}-e^{g \bar{T}+r(t-\tau-\bar{T})}\right]$

for $t \in[\tau+T, \tau+\bar{T}]$. 
At time $t$, a worker with birth date $\tau$ has NIPA income equal to $y_{1}(t, \tau) \equiv$ $r k(t, \tau)+(1-\theta) w(t)$ where $k(t, \tau)$ comes from (9), and a given retiree at time $t$ with birth date $\tau$ has $y_{2}(t, \tau) \equiv r k(t, \tau)+b(t)$ where $k(t, \tau)$ comes from (10). Hence, at time $t$ total NIPA income for all persons, $Y(t)$, can be found by integrating across birth dates

$$
\begin{aligned}
Y(t)= & \int_{t-T}^{t} N(t) e^{n(\tau-t)}[r k(t, \tau)+(1-\theta) w(t)] d \tau \\
& +\int_{t-\bar{T}}^{t-T} N(t) e^{n(\tau-t)}[r k(t, \tau)+b(t)] d \tau
\end{aligned}
$$

At time $t$, a worker with birth date $\tau$ saves $s_{1}(t, \tau) \equiv y_{1}(t, \tau)-c^{p}(t, \tau)$, and a given retiree at time $t$ with birth date $\tau$ saves $s_{2}(t, \tau) \equiv y_{2}(t, \tau)-c^{p}(t, \tau)$. Hence, at time $t$ the total flow of saving for all people, $S(t)$, can be found by integrating across birth dates

$$
S(t)=\int_{t-T}^{t} N(t) e^{n(\tau-t)} s_{1}(t, \tau) d \tau+\int_{t-\bar{T}}^{t-T} N(t) e^{n(\tau-t)} s_{2}(t, \tau) d \tau
$$

which can be rewritten as

$$
S(t)=Y(t)-\int_{t-\bar{T}}^{t} N(t) e^{n(\tau-t)} c^{p}(t, \tau) d \tau
$$

which is clearly equal to the total flow of transitory income.

This measure of personal saving is consistent with the one in the NIPA because $(i)$ both workers and retirees are included in the calculation, $(i i)$ personal income includes returns to private saving, but does not include withdrawals from savings accounts during retirement, (iii) social security taxation is not included as part of the personal income of workers while social security benefits are included as part of personal income for retirees, and $(i v)$ no distinction is drawn between spending on durables and perishables. Notice that the NIPA treat public and private pensions in the exactly opposite manner. Contributions to private pensions are included as part of income while contributions to public pensions are not. Likewise, distributions from public pensions are included as part of income while distributions from private pensions are not.

It is worth mentioning that within this model the NIPA personal saving rate can be positive only if there is growth in the economy (Modigliani 1986):

Proposition (Modigliani Stationary Equilibrium Concept). If growth in the real wage is zero $(x=0)$ and the population is stable $(n=0)$, then no matter what the rate of social security taxation, a zero NIPA personal saving 
rate is a feature of a rational expectations perfect-foresight equilibrium in which all consumers are optimally prepared for retirement.

Proof. The proof is tedious but straightforward so the algebraic steps are omitted. Evaluate (9), (10), (11), and (13) at $x=0$ and $n=0$, and then insert (9), (10), and (11) into (13); after many manipulations the result is $S(t)=0$. Q.E.D.

Corollary. Even more generally, it can be shown that $S(t)=0$ if $x=-n$.

Hence, there are two sources within the model for a non-zero NIPA personal saving rate: growth in the population and growth in real wages. Of course, a zero personal saving rate does not imply that the stock of total savings is zero, it instead implies that at any given time the saving of the young equals the dissaving of the old.

\subsection{General Equilibrium}

We now turn to the general equilibrium determination of factor prices. The analysis here follows Caliendo and Gahramanov (2008) almost exactly, up through equation (15). Total income (which is not the same thing as total personal income under NIPA accounting, $Y)$ is $Y^{\prime}(t)=K(t)^{\alpha}[A(t) L(t)]^{1-\alpha}$, where $K(t)=\int_{t-\bar{T}}^{t} N(t) e^{n(\tau-t)} k(t, \tau) d \tau$ is the total stock of capital at time $t, A(t)$ is the stock of labor-augmenting technology (where $\dot{A}(t)=x A(t)$ ), and $L(t)=$ $\int_{t-T}^{t} N(t) e^{n(\tau-t)} d \tau$ is the total number of workers (where $\dot{L}(t)=n L(t)$ ). Capital depreciates at rate $\delta$.

Definition (Stable Competitive Equilibrium). A stable competitive equilibrium is characterized by:

(i) $r(t)=\partial Y^{\prime}(t) / \partial K(t)-\delta=\alpha Y^{\prime}(t) / K(t)-\delta$,

(ii) $w(t)=\partial Y^{\prime}(t) / \partial L(t)=(1-\alpha) Y^{\prime}(t) / L(t)$,

(iii) $Y^{\prime}(t)=[r(t)+\delta] K(t)+w(t) L(t)$,

(iv) $\dot{r}(t)=0$ and $\dot{w}(t)=x w(t)$,

(v) consumers follow a permanent-income rule $c^{p}(t, \tau)=\Omega w(\tau) e^{g(t-\tau)}$.

This economy has a stable competitive equilibrium (see Caliendo and Gahramanov 2008 for a simple proof of existence) and it can be found by solving numerically the following implicit function of $K(t)$

$$
\begin{aligned}
K(t)= & \int_{t-\bar{T}}^{t} N(t) e^{n(\tau-t)} k(t, \tau) d \tau \\
= & z_{1}(t) q_{1}+z_{1}(t) q_{2}+z_{2}(t) q_{3}+z_{2}(t) q_{4} \\
& +z_{3}(t) q_{5}+z_{3}(t) q_{6}+z_{2}(t) q_{7}+z_{2}(t) q_{8}
\end{aligned}
$$

where 


$$
\begin{array}{ll}
z_{1}(t) \equiv \frac{N(t)(1-\theta) w(t)}{x-r} & z_{2}(t) \equiv \frac{N(t) w(t) \Omega}{g-r} \\
z_{3}(t) \equiv \frac{N(t) \theta w(t) R}{x-r} & q_{1} \equiv \frac{1-e^{-n T}}{n} \\
q_{2} \equiv \frac{1-e^{(r-x-n) T}}{r-x-n} & q_{3} \equiv \frac{1-e^{(r-x-n) T}}{x+n-r} \\
q_{4} \equiv \frac{1-e^{(g-x-n) T}}{g-x-n} & q_{5} \equiv \frac{e^{-n T}-e^{-n \bar{T}}}{n} \\
q_{6} \equiv \frac{e^{-(x+n) T+x \bar{T}+r(T-\bar{T})}-e^{-n \bar{T}}}{r-x-n} & q_{7} \equiv \frac{e^{-(x+n) T+g \bar{T}+r(T-\bar{T})}-e^{(g-x-n) \bar{T}}}{x+n-r} \\
q_{8} \equiv \frac{e^{(g-x-n) T}-e^{(g-x-n) \bar{T}}}{g-x-n} &
\end{array}
$$

Because $r(t)$ and $w(t)$ depend on $K(t),(14)$ is an implicit function that fully characterizes the equilibrium; this is a rather complicated non-linear function so I will resort to computing the value of $K(t)$ that solves (14) rather than deriving a closed-form solution.

From (13) and (8), the NIPA measure of personal saving in this general equilibrium competitive economy, at the stable equilibrium, is

$$
S(t)=Y(t)+\frac{N(t) \Omega w(t)}{g-x-n}\left[1-e^{(g-x-n) \bar{T}}\right]
$$

where $Y(t)$ comes from (11), which can be rearranged and integrated to obtain

$$
Y(t)=r K(t)+N(t)(1-\theta) w(t) q_{1}+N(t) b(t) q_{5}
$$

But the balanced budget constraint ensures

$$
b(t)=\theta w(t) R=\theta w(t) \frac{1-e^{-n T}}{e^{-n T}-e^{-n \bar{T}}}=\theta w(t) \frac{q_{1}}{q_{5}}
$$

hence

$$
Y(t)=r K(t)+N(t) w(t) q_{1}=r K(t)+w(t) L(t)=Y^{\prime}(t)-\delta K(t)
$$

It can be shown that $K(t)$ and $Y^{\prime}(t)$ both grow at rate $x+n$. Thus, $Y(t)$ grows at rate $x+n$, and with some straightforward manipulations it follows from (16) that $S(t)$ also grows at rate $x+n$. Hence, the saving rate is stationary in this competitive, stable equilibrium and I will evaluate it at $t=0$

$$
s=\frac{S(0)}{Y(0)}
$$

\section{Quantitative Analysis: The Effect of Social Security on Personal Saving}

The goals of this section are to $(i)$ calibrate the model to the U.S. economy in the 1970's when the personal saving rate was near 10 percent, (ii) check the robustness of the calibration, (iii) explore social security's role in the saving crisis, and $(i v)$ show the potential importance of the general equilibrium approach. 


\subsection{Baseline Calibration and Sensitivity Analysis}

Individuals work for 40 years and live for another 15 years after retirement before passing away and exiting the model (i.e., $T=40$ and $\bar{T}=55$ ). This corresponds to an agent who starts work at 25 , retires at 65 , and dies at 80 (which is the average date of death in the U.S. over the past few decades, see Bullard and Feigenbaum 2007). Because the individual supplies labor inelastically, he bears the full burden of the social security tax, so I will set $\theta=7 \%$ to reflect the full OASI rate (absent disability insurance and medicare) in the U.S. in the 1970's when the saving rate was around 10 percent.

Demographics and technology are normalized by $N(0)=1$ and $A(0)=1$. Bullard and Feigenbaum (2007) and Feigenbaum (2007) use a value of 1.56 percent for real wage growth in their macrocalibrations, and I will do likewise $(x=1.56 \%)$. The rate of population growth is set to $n=1 \%$ to reflect recent trends in the U.S. This value also conveniently produces a worker-to-retiree ratio of 3.5 (the ratio of workers to retirees has taken an average value of about 3.5 over the last few decades and this ratio has also been very stable over that period). ${ }^{3}$

Following convention, capital's share is set to $\alpha=35 \%$; and, loosely following Bullard and Feigenbaum (2007) and Feigenbaum (2007), I use $\delta=8 \%$ for the rate of capital depreciation, which conforms with the literature. Finally, I set $\sigma=1$, which follows convention and is also consistent with the balance of the micro evidence (Attanasio 1999).

The household discount rate is the only other free parameter, and I will choose it to try to match three targets:

- 3.5 percent for the real rate of return for the U.S. (following the recent macroeconomic work in life-cycle consumption, see Gourinchas and Parker 2002, Bullard and Feigenbaum 2007, Feigenbaum 2007)

- 3.0 for the capital-output ratio (Gourinchas and Parker 2002, Bullard and Feigenbaum 2007, Feigenbaum 2007)

- 10 percent for the NIPA personal saving rate (to reflect the average level during the 1970's before the collapse).

The value $\rho=2 \%$ is able to decently replicate these targets; the model predicts a real rate of return equal to 3.79 percent, a capital-output ratio equal to 3.0 , and a personal saving rate equal to 10.0 percent. This parameter $\rho$ was chosen according to:

$$
\rho=\underset{\rho \in \mathbb{R}^{+}}{\arg \min }\left\{\sum_{i} \omega_{i}\left[\frac{\nu_{c}^{i}-\nu_{t}^{i}}{\nu_{t}^{i}}\right]^{2}\right\}
$$

where $i$ indexes the targets, $\nu_{c}^{i}$ and $\nu_{t}^{i}$ are the endogenous variables at the calibrated and target values, respectively, and $\omega_{i}$ are the respective weights,

\footnotetext{
${ }^{3}$ See the 2006 OASDI Trustees Report.
} 
which I set to $1 / 3$. (Rather than fixing $\sigma=1$, I could leave this parameter free too and calibrate the pair $(\rho, \sigma)$ to minimize the right size of $(21)$, but the ultimate result does not change in a material way).

With this fit to the data the model appears to be a suitable instrument, and $\rho=2 \%$ is empirically reasonable and consistent with the literature as well. The calibrations of Bullard and Feigenbaum (2007) and Feigenbaum (2007) often involve a discount rate that is anywhere from 1 to 3.5 percentage points below the real rate of return, so there is a precedent in this literature for choosing a below-market discount rate, and this is common in macroeconomic models in general. Table 1 summarizes the baseline calibration.

Table 1. Baseline General Equilibrium Calibration: The NIPA Personal Saving Rate

\begin{tabular}{|c|c|c|c|}
\hline Parameter & Symbol & \multicolumn{2}{|c|}{ Value } \\
\hline Work life & $T$ & \multicolumn{2}{|c|}{40} \\
\hline Life span & $\bar{T}$ & \multicolumn{2}{|l|}{55} \\
\hline Social security tax rate & $\theta$ & \multicolumn{2}{|l|}{$7 \%$} \\
\hline Size of cohort 0 & $N(0)$ & \multicolumn{2}{|l|}{1} \\
\hline Technology & $A(0)$ & \multicolumn{2}{|l|}{1} \\
\hline Technology growth rate & $x$ & \multicolumn{2}{|c|}{$1.56 \%$} \\
\hline Population growth rate & $n$ & \multicolumn{2}{|c|}{$1 \%$} \\
\hline Capital's share & $\alpha$ & \multicolumn{2}{|l|}{$35 \%$} \\
\hline Depreciation rate & $\delta$ & \multicolumn{2}{|l|}{$8 \%$} \\
\hline Curvature parameter & $\sigma$ & \multicolumn{2}{|l|}{1} \\
\hline Discount rate & $\rho$ & \multicolumn{2}{|l|}{$2 \%$} \\
\hline Endogenous Variable & Symbol & Value & Target \\
\hline Real rate of return & $r$ & $3.79 \%$ & $3.5 \%$ \\
\hline Capital/output ratio & $K(0) / Y^{\prime}(0)$ & 3.0 & 3.0 \\
\hline Personal saving rate & $s$ & $10.0 \%$ & $10.0 \%$ \\
\hline
\end{tabular}

One desirable feature of this model is that there exists a large, empirically reasonable space for the unobservable preference parameters $\rho$ and $\sigma$ that is able to reproduce all three targets with reasonable accuracy and about as well as the baseline choice of these parameters. Table 2a shows a series of alternative calibrations for these unobservables, while holding all other parameters at baseline values. Each row is a separate steady-state calibration. It is clear from this table that the accuracy of the baseline calibration is not particularly sensitive to the choice of $\rho$ and $\sigma$; there are a number of alternative ordered pairs that can hit the data targets equally well. Actually, this result is not at all surprising. Feigenbaum (2008) points out that combinations of $\rho$ and $\sigma$ from a given level curve of the Euler equation produce equivalent micro-level behavior 
and hence are consistent with a single equilibrium of the model (i.e., $\rho$ and $\sigma$ are not separately identified). So, in fact, the results of Table 2 a could look even stronger if I had followed such a level curve, whereas instead I followed the curve only approximately.

Likewise, on the production side there is a large space of $\alpha$ and $\delta$ that is also able to decently reproduce all three targets. Table $2 \mathrm{~b}$ reports some of these alternative calibrations and it is again clear that many other possible combinations of these production parameters will work. The baseline calibration is fairly robust to the utility-side parameters and the production-side parameters.

Table 2a. Alternative General Equilibrium Calibrations: Sensitivity to Unobservable Parameters $\rho$ and $\sigma$

\begin{tabular}{|c|c|c|c|c|}
\hline \multicolumn{2}{|c|}{ Unobservables } & \multicolumn{3}{|c|}{ Endogenous Variables } \\
\hline$\rho$ & $\sigma$ & $s$ & $K(0) / Y^{\prime}(0)$ & $r$ \\
\hline $0.5 \%$ & 1.8 & $10.0 \%$ & 3.0 & $3.73 \%$ \\
\hline $1 \%$ & 1.5 & $10.1 \%$ & 3.0 & $3.69 \%$ \\
\hline $1.5 \%$ & 1.2 & $10.1 \%$ & 3.0 & $3.66 \%$ \\
\hline $2 \%$ & 1.0 & $10.0 \%$ & 3.0 & $3.79 \%$ \\
\hline $2.5 \%$ & 0.7 & $10.0 \%$ & 3.0 & $3.75 \%$ \\
\hline $3 \%$ & 0.4 & $10.0 \%$ & 3.0 & $3.72 \%$ \\
\hline $3.5 \%$ & 0.2 & $9.9 \%$ & 3.0 & $3.86 \%$ \\
\hline
\end{tabular}

NOTE: All other parameters are fixed at baseline values.

Table 2b. Alternative General Equilibrium Calibrations: Sensitivity to Production Parameters $\alpha$ and $\delta$

\begin{tabular}{cccccc}
\hline \multicolumn{4}{c}{ Sensitivity to Production Parameters $\alpha$ and $\delta$} \\
\hline \multicolumn{3}{c|}{$\begin{array}{c}\text { Parameters } \\
\alpha\end{array}$} & \multicolumn{4}{c}{ Endogenous Variables } \\
\hline $25 \%$ & $3.5 \%$ & $10.0 \%$ & 3.4 & $3.79 \%$ \\
$27.5 \%$ & $4.5 \%$ & $10.0 \%$ & 3.3 & $3.79 \%$ \\
$30 \%$ & $5.5 \%$ & $10.0 \%$ & 3.2 & $3.81 \%$ \\
$32.5 \%$ & $6.5 \%$ & $10.1 \%$ & 3.1 & $3.83 \%$ \\
$35 \%$ & $8 \%$ & $10.0 \%$ & 3.0 & $3.79 \%$ \\
$37.5 \%$ & $9 \%$ & $10.1 \%$ & 2.9 & $3.84 \%$ \\
$40 \%$ & $10.5 \%$ & $10.1 \%$ & 2.8 & $3.83 \%$ \\
\multicolumn{4}{r}{ NOTE: All other parameters are fixed at baseline values. }
\end{tabular}

\subsection{Main Results: The Impact of Social Security Growth}

Let's return to the baseline calibration and focus on the question at hand: what is the effect on personal saving of a large increase in the social security tax rate? 
Recomputing the model under the assumption $\theta=10.6 \%$ for consistency with the state of the world in which we presently live, while leaving other parameters at baseline values, will produce the following alternative equilibrium: the real interest rate is 4.14 percent, the capital-output ratio is 2.9 , and the personal saving rate is 9.6 percent. Hence, the model predicts that even a large change in the social security tax rate would have a very modest effect on the NIPA personal saving rate.

Why is this? How can this result be possible, given that we know from both theory and empirical evidence that social security should reduce the level of saving for retirement? The key, however, is to recognize that household preparedness for retirement and NIPA personal saving are not at all the same thing. The NIPA personal saving rate includes both workers and retirees in the calculation. Workers generally have positive saving rates and retirees have negative saving rates in the model economy. And the above proposition and proof make it clear that growth in the population and growth in technology are the salient factors that allow for a positive aggregate saving rate along a balanced growth path. Basically, growth ensures that the positive saving rates among the workers will dominate the negative saving rates among the retirees. Apparently, almost everything else, including social security, is just a side show in the model. True, growth in social security reduces the size of the aggregate capital stock, but this does not necessarily translate into a significant reduction in personal saving, at least not the way the government defines personal saving in the NIPA.

This result is very robust to the choice of the unobservable preference parameters. Let's consider $(\rho, \sigma)$ ordered pairs from the closed rectangle $\rho \in$ $[1 \%, 6 \%], \sigma \in[1,5]$, in order to study a wide space of alternative values that sometimes appear in the literature. The change in the saving rate resulting from an increase in the social security tax rate from 7 percent to 10.6 percent is most pronounced when $\rho$ is low and there is no clear relationship with $\sigma$, but the change in the saving rate is remarkably robust to such variation in these unobservable preference parameters and never climbs much above $1 / 2$ of a percentage point. Table 3 a reports these results.

It is also important to check the sensitivity of the baseline result to the degree of growth in the economy. We know from the work of Modigliani (1986) and from the proposition above that total personal saving in an economy full of life-cycle permanent-income consumers will be zero if the population is stable and if there is no technological advancement (the dissaving of the old will exactly offset the saving of the young). Hence, social security can only affect the personal saving rate if there is growth in the economy. I consider $(x, n)$ ordered pairs from the closed rectangle $x \in[0.5 \%, 2 \%], n \in[0.5 \%, 2 \%]$. As expected, the effect of a change in the social security tax becomes more pronounced as $x$ and $n$ increase. But even when $x=n=2 \%$ the change in the personal saving rate will still be on the order of $1 / 2$ of a percentage point. Table $3 \mathrm{~b}$ reports these results. 
Table 3a. The General Equilibrium Effect of a 50\% Increase in Social Security Taxation on the NIPA Personal Saving Rate: Robustness to Unobservable Preference Parameters

\begin{tabular}{|c|c|c|c|c|c|c|}
\hline & & \multicolumn{5}{|c|}{$\sigma$} \\
\hline & $1 \%$ & -0.4 points & -0.6 points & -0.6 points & -0.6 points & -0.4 points \\
\hline & $2 \%$ & -0.4 points & -0.5 points & -0.4 points & -0.4 points & -0.3 points \\
\hline$\rho$ & $3 \%$ & -0.3 points & -0.3 points & -0.4 points & -0.4 points & -0.3 points \\
\hline & $4 \%$ & -0.3 points & -0.3 points & -0.3 points & -0.3 points & -0.3 points \\
\hline & $5 \%$ & -0.2 points & -0.3 points & -0.2 points & -0.3 points & -0.2 points \\
\hline & $6 \%$ & -0.2 points & -0.2 points & -0.2 points & -0.2 points & -0.2 points \\
\hline
\end{tabular}

Table 3b. The General Equilibrium Effect of a $50 \%$ Increase in Social Security Taxation on the NIPA Personal Saving Rate: Robustness to Population and Productivity Growth

\begin{tabular}{cc|cccc} 
& & \multicolumn{4}{|c}{$n$} \\
& & $0.5 \%$ & $1.0 \%$ & $1.5 \%$ & $2.0 \%$ \\
\hline \multirow{3}{*}{$x$} & $0.5 \%$ & -0.1 points & -0.3 points & -0.4 points & -0.4 points \\
& $1.0 \%$ & -0.2 points & -0.3 points & -0.4 points & -0.5 points \\
& $1.5 \%$ & -0.3 points & -0.4 points & -0.4 points & -0.6 points \\
& $2.0 \%$ & -0.3 points & -0.4 points & -0.5 points & -0.6 points
\end{tabular}

There doesn't seem to be any reasonable parameterization in this model that might support the thesis that social security has a significant effect on NIPA personal saving, even if it causes pronounced distortions to micro-level saving profiles. To drive this point home, consider the counterfactual case of a decrease in the social security tax rate from 7 percent to zero, which would cause only a slight increase in the saving rate from 10 percent to 10.9 percent in the general equilibrium model. There just isn't much action along this dimension in the model, unless the general equilibrium feedback effects are ignored (see below).

\subsection{A Digression: Impatience Among the Rising Genera- tion?}

A different hypothesis that is common in the popular press is that the collapse in personal saving could be the result of growing impatience among the rising generation. Parker (1999) uses the Ramsey growth model to lend support to this hypothesis. The usual argument goes something like this: life is full of stories about young people wanting to enjoy right now the life style that their parents 
enjoy, perhaps failing to recognize that it took their parents many years of hard work and prudent financial decision making in order to reach that point. Likewise, the household debt-to-income ratio is at a record high in the U.S. (Lansing 2005), and so is credit card debt. The present model can be used to study this hypothesis. For example, recall that $s=10 \%$ in the baseline calibration with $\rho=2 \%$; and, a separate steady state with say $\rho=4 \%$ produces $s=8.2 \%$. This mechanism operates in the expected direction and seems to have a significant effect, unlike the social security tax rate.

\subsection{The Importance of the General Equilibrium Approach}

To emphasize the potential importance of the general equilibrium approach, I exogenously set factor prices at their baseline values $(r=3.79 \%$ and $w(0)=$ 1.17). Holding factor prices at these values and setting all other parameters at their baseline values from Table 1, an increase in the social security tax rate from 7 percent to 10.6 percent will cause the personal saving rate to drop from 10.0 percent to 8.1 percent. Ignoring the general equilibrium effects will make social security appear much more important in contributing to the declining personal saving rate - in partial equilibrium it appears that about 20 percent of the drop can be pinned on social security.

\section{Summary of Findings and Direction for Fu- ture Work}

Growth in the social security tax rate from about 7 percent in the 1970's and early 1980 's to 10.6 percent today may be responsible for very little of the collapse in the personal saving rate in the U.S. This result may be considered significant because theory predicts that a massive increase in the size of the social security program should produce a large negative effect on household saving for retirement (e.g., Feldstein 1974) —indeed this is a feature of the present model too. But household preparedness for retirement and NIPA personal saving are not the same thing, despite the apparent trend in the popular press to treat these two things as equal. In sum, even though social security has important effects on wealth accumulation for retirement, there is no evidence in the general equilibrium model studied here that social security has played an important role in the recent collapse of the NIPA personal saving rate.

There are a number of areas in which this paper could be extended. First, behavior at the micro level is defined by the standard permanent-income rule. This is a strong assumption. Many behavioral economists think the permanentincome rule is more normative than positive, and so it would be interesting to see how the results hold up under different assumptions about the way people behave. Perhaps a model that allowed for some behavioral defect such as hyperbolic preferences, short planning horizons, etc., would lead to a different set of quantitative results. 
Second, a much richer set of macro data targets could be studied. Perhaps most importantly, aggregate life-cycle consumption is well-known to be humpshaped over the life cycle, with a peak near age 50. The aggregate consumption profile in the above model increases monotonically, which is the result of the assumptions in the simple model without any behavioral defect and without any uncertainty. Perhaps a richer model that is capable of hitting additional important targets would also lead to different conclusions about the role of social security.

Third, this study only considers the effect of social security on personal saving by comparing steady state equilibria. To the extent that transition dynamics are important for assessing the role of social security, the present paper would provide an incomplete picture.

\section{References}

[1] Attanasio, Orazio (1999), Consumption, in John B. Taylor and Michael Woodford, eds., Handbook of Macroeconomics, Volume 1B, 741-812.

[2] Bullard, James and James Feigenbaum (2007), A Leisurely Reading of the Life Cycle Consumption Data. Journal of Monetary Economics, forthcoming.

[3] Caliendo, Frank and Emin Gahramanov (2008), Hunting the Unobservables for Optimal Social Security: A General Equilibrium Approach. Working Paper, Utah State University.

[4] Cremer, Helmuth, Philippe De Donder, Dario Maldonado, and P. Pestieau (2006), Designing a Linear Pension Scheme with Forced Savings and Wage Heterogeneity. International Tax and Public Finance, forthcoming.

[5] Feigenbaum, James (2007), Can Mortality Risk Explain the Consumption Hump? Journal of Macroeconomics, forthcoming.

[6] Feigenbaum, James (2008), Precautionary Saving Unfettered. Working Paper, University of Pittsburgh.

[7] Feldstein, Martin (1974), Social Security, Induced Retirement and Aggregate Capital Accumulation. Journal of Political Economy 82, 905-926.

[8] Feldstein, Martin (1985), The Optimal Level of Social Security Benefits. Quarterly Journal of Economics 100(2), 303-320.

[9] Feldstein, Martin (1987), Should Social Security Benefits Be Means Tested? Journal of Political Economy 95(3), 468-484.

[10] Gale, William G. and John Sabelhaus (1999), Perspectives on the Household Saving Rate. Brookings Papers on Economic Activity 1, 181-224.

[11] Garner, C. Alan (2006), Should the Decline in the Personal Saving Rate Be a Cause for Concern? Economic Review, Federal Reserve Bank of Kansas City, 5-28. 
[12] Gokhale, Jagadeesh, Laurence J. Kotlikoff, and John Sabelhaus (1996), Understanding the Postwar Decline in U.S. Saving: A Cohort Analysis. Brookings Papers on Economic Activity 1, 315-407.

[13] Gourinchas, Pierre-Olivier and Jonathan A. Parker (2002), Consumption Over the Life Cycle. Econometrica 70, 47-89.

[14] Lansing, Kevin J. (2005), Spendthrift Nation. Federal Reserve Bank of San Francisco Economic Letter 2005-30.

[15] Lusardi, Annamaria, Jonathan Skinner, and Steven Venti (2001), Saving Puzzles and Saving Policies in the United States. Oxford Review of Economic Policy 17(1), 95-115.

[16] Marquis, Milt (2002), What's Behind the Low U.S. Personal Saving Rate? Federal Reserve Bank of San Francisco Economic Letter 2002-09.

[17] Modigliani, Franco (1986), Life Cycle, Individual Thrift, and the Wealth of Nations. American Economic Review 76(3), 297-313.

[18] Munnell, Alicia H., Francesca Golub-Sass, and Andrew Varani (2005), How Much is the Working-Age Population Saving? Center for Retirement Reseach at Boston College, working paper.

[19] Parker, Jonathan (1999), Spendthrift in America? On Two Decades of Decline in the U.S. Saving Rate. In Ben Bernanke and Julio Rotemberg eds., NBER Macroeconomics Annual 1999, Vol 14, 317-370.

[20] Reis, Ricardo (2006), Inattentive Consumers. Journal of Monetary Economics 53(8), 1761-1800. 


\section{CESifo Working Paper Series}

for full list see www.cesifo-group.org/wp

(address: Poschingerstr. 5, 81679 Munich, Germany, office@cesifo.de)

2685 Peter Egger, Christian Keuschnigg and Hannes Winner, Incorporation and Taxation: Theory and Firm-level Evidence, June 2009

2686 Chrysovalantou Milliou and Emmanuel Petrakis, Timing of Technology Adoption and Product Market Competition, June 2009

2687 Hans Degryse, Frank de Jong and Jérémie Lefebvre, An Empirical Analysis of Legal Insider Trading in the Netherlands, June 2009

2688 Subhasish M. Chowdhury, Dan Kovenock and Roman M. Sheremeta, An Experimental Investigation of Colonel Blotto Games, June 2009

2689 Alexander Chudik, M. Hashem Pesaran and Elisa Tosetti, Weak and Strong Cross Section Dependence and Estimation of Large Panels, June 2009

2690 Mohamed El Hedi Arouri and Christophe Rault, On the Influence of Oil Prices on Stock Markets: Evidence from Panel Analysis in GCC Countries, June 2009

2691 Lars P. Feld and Christoph A. Schaltegger, Political Stability and Fiscal Policy - Time Series Evidence for the Swiss Federal Level since 1849, June 2009

2692 Michael Funke and Marc Gronwald, A Convex Hull Approach to Counterfactual Analysis of Trade Openness and Growth, June 2009

2693 Patricia Funk and Christina Gathmann, Does Direct Democracy Reduce the Size of Government? New Evidence from Historical Data, 1890-2000, June 2009

2694 Kirsten Wandschneider and Nikolaus Wolf, Shooting on a Moving Target: Explaining European Bank Rates during the Interwar Period, June 2009

2695 J. Atsu Amegashie, Third-Party Intervention in Conflicts and the Indirect Samaritan's Dilemma, June 2009

2696 Enrico Spolaore and Romain Wacziarg, War and Relatedness, June 2009

2697 Steven Brakman, Charles van Marrewijk and Arjen van Witteloostuijn, Market Liberalization in the European Natural Gas Market - the Importance of Capacity Constraints and Efficiency Differences, July 2009

2698 Huifang Tian, John Whalley and Yuezhou Cai, Trade Sanctions, Financial Transfers and BRIC's Participation in Global Climate Change Negotiations, July 2009

2699 Axel Dreher and Justina A. V. Fischer, Government Decentralization as a Disincentive for Transnational Terror? An Empirical Analysis, July 2009 
2700 Balázs Égert, Tomasz Koźluk and Douglas Sutherland, Infrastructure and Growth: Empirical Evidence, July 2009

2701 Felix Bierbrauer, Optimal Income Taxation and Public Goods Provision in a Large Economy with Aggregate Uncertainty, July 2009

2702 Marc Gronwald, Investigating the U.S. Oil-Macroeconomy Nexus using Rolling Impulse Responses, July 2009

2703 Ali Bayar and Bram Smeets, Government Deficits in the European Union: An Analysis of Entry and Exit Dynamics, July 2009

2704 Stergios Skaperdas, The Costs of Organized Violence: A Review of the Evidence, July 2009

2705 António Afonso and Christophe Rault, Spend-and-tax: A Panel Data Investigation for the EU, July 2009

2706 Bruno S. Frey, Punishment - and beyond, July 2009

2707 Michael Melvin and Mark P. Taylor, The Crisis in the Foreign Exchange Market, July 2009

2708 Firouz Gahvari, Friedman Rule in a Model with Endogenous Growth and Cash-inadvance Constraint, July 2009

2709 Jon H. Fiva and Gisle James Natvik, Do Re-election Probabilities Influence Public Investment?, July 2009

2710 Jarko Fidrmuc and Iikka Korhonen, The Impact of the Global Financial Crisis on Business Cycles in Asian Emerging Economies, July 2009

2711 J. Atsu Amegashie, Incomplete Property Rights and Overinvestment, July 2009

2712 Frank R. Lichtenberg, Response to Baker and Fugh-Berman's Critique of my Paper, "Why has Longevity Increased more in some States than in others?", July 2009

2713 Hans Jarle Kind, Tore Nilssen and Lars Sørgard, Business Models for Media Firms: Does Competition Matter for how they Raise Revenue?, July 2009

2714 Beatrix Brügger, Rafael Lalive and Josef Zweimüller, Does Culture Affect Unemployment? Evidence from the Röstigraben, July 2009

2715 Oliver Falck, Michael Fritsch and Stephan Heblich, Bohemians, Human Capital, and Regional Economic Growth, July 2009

2716 Wladimir Raymond, Pierre Mohnen, Franz Palm and Sybrand Schim van der Loeff, Innovative Sales, R\&D and Total Innovation Expenditures: Panel Evidence on their Dynamics, July 2009 
2717 Ben J. Heijdra and Jochen O. Mierau, Annuity Market Imperfection, Retirement and Economic Growth, July 2009

2718 Kai Carstensen, Oliver Hülsewig and Timo Wollmershäuser, Price Dispersion in the Euro Area: The Case of a Symmetric Oil Price Shock, July 2009

2719 Katri Kosonen and Gaëtan Nicodème, The Role of Fiscal Instruments in Environmental Policy, July 2009

2720 Guglielmo Maria Caporale, Luca Onorante and Paolo Paesani, Inflation and Inflation Uncertainty in the Euro Area, July 2009

2721 Thushyanthan Baskaran and Lars P. Feld, Fiscal Decentralization and Economic Growth in OECD Countries: Is there a Relationship?, July 2009

2722 Nadia Fiorino and Roberto Ricciuti, Interest Groups and Government Spending in Italy, 1876-1913, July 2009

2723 Andreas Wagener, Tax Competition, Relative Performance and Policy Imitation, July 2009

2724 Hans Fehr and Fabian Kindermann, Pension Funding and Individual Accounts in Economies with Life-cyclers and Myopes, July 2009

2725 Ernesto Reuben and Arno Riedl, Enforcement of Contribution Norms in Public Good Games with Heterogeneous Populations, July 2009

2726 Kurt Schmidheiny and Marius Brülhart, On the Equivalence of Location Choice Models: Conditional Logit, Nested Logit and Poisson, July 2009

2727 Bruno S. Frey, A Multiplicity of Approaches to Institutional Analysis. Applications to the Government and the Arts, July 2009

2728 Giovanni Villani, A Strategic R\&D Investment with Flexible Development Time in Real Option Game Analysis, July 2009

2729 Luca Di Corato and Michele Moretto, Investing in Biogas: Timing, Technological Choice and the Value of Flexibility from Inputs Mix, July 2009

2730 Gilad D. Aharonovitz, Nathan Skuza and Faysal Fahs, Can Integrity Replace Institutions? Theory and Evidence, July 2009

2731 Michele Moretto and Sergio Vergalli, Managing Migration through Conflicting Policies: an Option-theory Perspective, July 2009

2732 Volker Nitsch, Fly or Cry: Is Airport Noise Costly?, July 2009

2733 Francesco Cinnirella and Joachim Winter, Size Matters! Body Height and Labor Market Discrimination: A Cross-European Analysis, July 2009 
2734 Samuel Bowles and Sandra Polanía Reyes, Economic Incentives and Social Preferences: A Preference-based Lucas Critique of Public Policy, July 2009

2735 Gary Burtless, Lessons of the Financial Crisis for the Design of National Pension Systems, July 2009

2736 Helmuth Cremer, Firouz Gahvari and Pierre Pestieau, Fertility, Human Capital Accumulation, and the Pension System, July 2009

2737 Hans Jarle Kind and Frank Stähler, Market Shares in Two-Sided Media Industries, July 2009

2738 Pamela Campa, Alessandra Casarico and Paola Profeta, Gender Culture and Gender Gap in Employment, August 2009

2739 Sebastian Gechert, Supplementary Private Health Insurance in Selected Countries: Lessons for EU Governments?, August 2009

2740 Leif Danziger, Endogenous Monopsony and the Perverse Effect of the Minimum Wage in Small Firms, August 2009

2741 Yan Dong and John Whalley, A Third Benefit of Joint Non-OPEC Carbon Taxes: Transferring OPEC Monopoly Rent, August 2009

2742 Valentina Bosetti, Carlo Carraro and Massimo Tavoni, Climate Change Mitigation Strategies in Fast-Growing Countries: The Benefits of Early Action, August 2009

2743 Christina Felfe, The Willingness to Pay for Job Amenities: Evidence from Mothers' Return to Work, August 2009

2744 Jörg Franke, Christian Kanzow, Wolfgang Leininger and Alexandra Väth, Effort Maximization in Asymmetric N-Person Contest Games, August 2009

2745 Bruno S. Frey and Paolo Pamini, Making World Heritage Truly Global: The Culture Certificate Scheme, August 2009

2746 Frank N. Caliendo, Is Social Security behind the Collapse of Personal Saving?, August 2009 